\title{
Análise da Experiência dos Usuários da plataforma virtual Balcão de Oportunidades Birigui
}

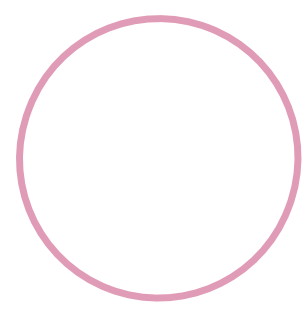

User Experience analysis of 'Balcão de Oportunidades Birigui' virtual platform

\section{Cláudio Roberto Boni}

Universidade Estadual Paulista

claudioboni@hotmail.com $\mathbf{x}$

Conrado Renan da Silva

Universidade Estadual Paulista

conradorenansilva@gmail.com $\mathbf{x}$

\section{Camila Medina}

Universidade Estadual Paulista

c.medina@unesp.br $\boldsymbol{x}$

Mariana Petruccelli Pires

Universidade Estadual Paulista

marianapetru@hotmail.com $\mathbf{x}$

Luis Carlos Paschoarelli

Universidade Estadual Paulista

luis.paschoarelli@unesp.br.M

Emilene Zitkus

University of Huddersfield School of Art Design and Architecture

emilenezitkus@gmail.com

\section{PROJËTICA}

\section{COMO CITAR ESTE ARTIGO:}

BONI, Cláudio Roberto et al. Análise da experiência dos usuários da plataforma virtual Balcão de Oportunidades Birigui. Projética, Londrina, v. 12, n. 1, p. 195219, 2021

DOI: 10.5433/2236-2207.2021v12n1p195

Submissão: 28-06-2019

Aceite: 18-11-2019 
RESUMO: Atualmente, sites de busca e oferta de emprego têm se tornado importantes artefatos comunicacionais que auxiliam indivíduos na recolocação no mercado de trabalho. O presente estudo busca avaliar a experiência do usuário (UX) frente ao Site do Balcão de Oportunidades da Prefeitura Municipal de Birigui, SP. Participaram da pesquisa indivíduos desempregados $(n=5)$ que já estavam cadastrados no sistema. O estudo apontou uma série de oportunidades de melhoria no design da plataforma, que teria impacto direto na experiência dos usuários.

Palavras-chave: Experiência do usuário. Digital. Emprego. Serviço.

\begin{abstract}
Currently, employment search engines and offer websites have become important communication tools that help people with their repositioning in the labor market. The present study aims to evaluate the user experience (UX) at the Birigui City Hall Opportunities Desk Website (in the state of São Paulo). Unemployed people who were previously registered in the system participated in the research $(n=5)$. The research pointed to several opportunities for improving the platform design, which would have a direct impact on the users' experience.
\end{abstract}

Keywords: User experience. Digital. Employment. Service.

\title{
1 INTRODUÇÃo
}

Uma das preocupações da sociedade atual é a substituição da mão-de-obra humana pela tecnologia. Isso tem sido tema de estudos acadêmicos e mercadológicos ao redor do mundo. Há uma insegurança em relação ao que a tecnologia pode realmente trazer para a sociedade no futuro. A questão é saber quais as estratégias 
a serem utilizadas para garantir que o homem esteja no controle. Uma iminente premissa é a de que o homem deva ter, cada vez mais, domínio da tecnologia disponível para constantemente evoluir como ser humano.

Neste sentido, a relação trabalho e tecnologia deve ser tratada de forma assertiva. O que se sabe é que crises econômicas trazem consigo diversas consequências, como o aumento da taxa de desemprego, que se reflete no crescimento dos postos de trabalho informais e na maior rotatividade nos postos assalariados formais (POCHMANN, 2009). Como exemplo, o número de pessoas desocupadas, junto à população em idade ativa no Brasil, passou de 6,75 milhões em 2014 para 13,23 milhões em 2017. A faixa etária da população mais atingida eram indivíduos com idades entre 18 e 24 anos (32,6\%) e de 25 a 39 (34,7\%) anos (IBGE, 2018).

Sites de ofertas de emprego, objeto deste estudo, estão alterando as formas como as pessoas buscam por trabalho e as empresas identificam e buscam por talentos (MANYIKA, 2017). Atualmente, para auxiliar a busca do indivíduo por vagas de emprego disponíveis, existem iniciativas de agências governamentais. Por exemplo, no Estado de São Paulo, o “Portal Emprega São Paulo1", disponibiliza encaminhamentos a oportunidades de emprego. Portanto, trata-se de ferramentas e tecnologias que utilizam técnicas de interação humano-computador para fomentar o capital social, atender às necessidades dessa população e promover o desenvolvimento econômico e sustentável (JEN et al., 2014).

A falta de infraestrutura está atrasando os benefícios digitais para algumas economias emergentes; parcerias público-privadas podem ajudar a resolver as falhas do mercado (MANYIKA, 2017). Com isso, entra em cena o termo User Experience (UX), que é utilizado para sintetizar toda experiência com um produto físico ou digital, não somente suas funcionalidades, mas também o quanto um sistema é agradável ao usuário (LOWDERNILK, 2013). Pesquisas em UX e o User Interface (UI) estão entre os processos mais buscados por empresas como forma

[1] Pesquisado em: https://www.empregasaopaulo.sp.gov.br/imoweb/ 
de aprimorar o design de produtos e sistemas, porém como destaca Nojimoto (2009), essas propostas não se encerram no artefato em si, mas buscam no homem a fonte para o desenvolvimento de seus produtos de maneira contínua.

De acordo com o exposto, o presente artigo baseia-se no contexto de Design Centrado no Usuário e do UX, no tocante à avaliação de um portal de oportunidades de emprego, de acordo com técnicas de pesquisa qualitativa, comumente utilizadas em análises de experiência do usuário. Para tal, o objetivo foi avaliar a experiência dos usuários em relação ao website do Balcão de Oportunidades Birigui e fornecer diretrizes operacionalizáveis para o design da plataforma, melhorando a interface de uso.

\section{FUNDAMENTAÇÃO TEÓRICA - DESIGN CENTRADO NO USUÁRIO E UX}

A aproximação do design a áreas como a psicologia, a engenharia de software, a análise e desenvolvimento de sistema, a sociologia e outras mais tem deixado sua atuação mais holística e consciente na geração de soluções que envolvam a tecnologia e as pessoas. O que se deve ter em mente acerca desta discussão é a importância de se colocar as pessoas à frente dos projetos de design. E entender que o trabalho com o ser humano é algo sério e complexo, por isso, o propósito do design com outras áreas é, além de assumir suas limitações, trazer novos conhecimentos e abordagens para o campo do design.

O que se conhece do design centrado no usuário surgiu da interação humano-computador e consiste em uma metodologia de design de software para desenvolvedores e designers, que os auxilia a criar aplicativos que atendam às necessidades de seus usuários. A questão principal é a usabilidade que vai permitir que se coloque os usuários no centro de seu processo de desenvolvimento, eliminará a ambiguidade e chegará ao ponto central de suas necessidades (LOWDERNILK, 2013). Para isso, o design necessita do apoio de áreas que saibam pesquisar as pessoas não apenas fisicamente, mas psicológica e emocionalmente, somado ao conhecimento de áreas que saibam desenvolver tecnologia. 
OUX, no entanto, se popularizou na década de 90 , com os avanços da internet e da informação, e na busca de melhorias dos produtos e serviços destinados aos usuários. Nasceu para suprir a necessidade de tornar as máquinas mais intuitivas e fáceis de serem operadas. Atualmente, o termo, já popularizado, possui algumas ramificações, como UI, UX Strategy, que também estão direcionadas para a relação do produto/serviço com o usuário para garantir uma melhor experiência.

As experiências dos usuários são subjetivas, profissionais de design projetam a interface com o intuito de que o usuário obtenha uma relação intuitiva com a interface, sem precisar de auxílio externo (TEIXEIRA, 2013). Além de encontrar a melhor solução para os usuários, o UX também define qual problema precisa ser resolvido na interface, para quem esse problema precisa ser resolvido e qual o melhor caminho para resolvê-lo. (HESS, 2010). Isso tem muita relevância, tendo-se em vista o fato de os usuários de tecnologia estarem se tornando um grupo mais experiente e mais exigente. Atualmente os usuários esperam ter uma experiência rica, desejam usar aplicativos que tenham sido pensados de forma inteligente e que sejam agradáveis (LOWDERNILK, 2013).

A usabilidade e acessibilidade entram neste contexto, pois são termos que se conectam, uma vez que cada uma delas apresenta um papel específico para estabelecer pleno uso do sistema. A usabilidade tem como preocupação central garantir o uso de todos os potenciais de um dado sistema interativo, enquanto a acessibilidade estabelece-se como garantia de que esse mesmo sistema é universal e passível de ser utilizado por todos os usuários, independentemente de suas limitações (RIBEIRO, 2012). Projeção de artefatos que garantam ambas qualificações deve, obrigatoriamente, alinhar-se às necessidades psicológicas e físicas das pessoas operantes.

Para Nielsen (1993), a usabilidade e a qualidade de uso possuem os mesmos princípios. Para que um sistema seja bem-sucedido deve ser usável e útil simultaneamente, deve providenciar as características necessárias para que o usuário cumpra uma determinada tarefa e a consiga fazer de forma rápida, eficiente e intuitiva. Os cinco principais atributos para a usabilidade, segundo Nielsen (1993), são: 
1. Capacidade de aprendizagem: será a primeira experiência com o sistema. Quanto mais rápida a capacidade de aprendizagem, maior será o grau de satisfação e confiança com o qual o usuário interage com o sistema.

2. Capacidade de memorização: ao olhar para um website, quanto menos complexo for a sua interface, maior a probabilidade de um usuário voltar a usar depois de um tempo de inatividade sem a necessidade de ter que reaprender a usar.

3. Eficiência na utilização: o grau de rapidez e sucesso com que os usuários atingem seus objetivos na interação com um sistema.

4. Fiabilidade da utilização: quantidade de ocasiões em que ocorrem erros e a facilidade com que são resolvidos.

5. Satisfação do usuário: a satisfação do usuário é subjetiva. Para Nielsen (1993), o grau de satisfação pode ter duas dimensões: uma funcional, que mede a capacidade do sistema em providenciar as ferramentas necessárias para que o usuário cumpra com sucesso as tarefas, e outra, visual, baseada na emoção positiva ou negativa criada pelo design da interface, independentemente da sua funcionalidade.

De acordo com Teixeira (2013), a melhor alternativa para uma boa usabilidade é oferecer informações em pequenas doses, já que o usuário é incapaz de assimilar muitas informações quando está realizando alguma tarefa. A hierarquia também favorece o usuário, utilizando diferentes estilos visuais para os elementos da tela, de maneira a priorizar o que é mais importante, dessa maneira é possível guiar os olhos do usuário pelo caminho que ele deve percorrer.

Ao se analisar a experiência do usuário em um determinado software, devese levar em consideração tanto os iniciantes quanto os usuários experientes, e sua interface deve propor diferentes meios para que ambos tenham facilidade de usar suas funções, sem a necessidade de personalizá-las (CYBIS; BETIOL; FAUST, 2015). Por fim, além das questões técnicas e quantificáveis, o designer de interfaces deve ter como princípio o entendimento das reais necessidades das pessoas, em todas 
as suas vertentes, correlacionando essas informações às diretrizes já estabelecidas pela bibliografia, sobre o UX e design centrado nas pessoas.

\section{MATERIAL E MÉTODOS}

Este estudo tem caráter exploratório e qualitativo (CRESWELL, 2007), e busca entender os significados que pessoas ou grupos dão a um determinado problema social. Neste caso, houve interesse em avaliar a experiência dos usuários do serviço Balcão de Oportunidades Birigui² ${ }^{2}$.

O Balcão de Oportunidades Birigui é um serviço gratuito, lançado em 2015 pela Prefeitura Municipal de Birigui (SP), que tem como finalidade prestar atendimento aos cidadãos que buscam oportunidades de emprego, cursos de qualificação e capacitação. O serviço dá acesso a empresas que queiram divulgar vagas de emprego e/ou buscam currículos de profissionais. Parte do serviço prestado é virtual e pode ser acessada por meio de uma plataforma online. Contudo, a efetivação do cadastro do currículo é feita presencialmente. Embora o Balcão de Oportunidades Birigui seja destinado também às empresas, esta pesquisa avaliou somente as experiências de indivíduos que estavam em busca de recolocação no mercado de trabalho.

\subsection{Procedimentos}

O estudo apresentou nove etapas metodológicas, sendo seu núcleo caracterizado pelos tópicos de 4 a 8:

1. Planejamento: Nesta etapa, definiu-se o objetivo da pesquisa, o escopo, o cronograma, as técnicas, a equipe de profissionais, o que se buscava medir e a

[2] Consultado em: http://www.balcaodeoportunidadesbirigui.com/ 
caracterização da amostra. A equipe de levantamento de dados foi composta por dois designers (um mestrando e um doutorando) e uma psicóloga.

2. Preparação: Nesta etapa, vários aspectos foram operacionalizados, convertendo-se determinações estratégicas em itens práticos. Um deles foi a definição de um local (sala isolada), na qual foi disposto apenas um notebook com acesso à internet de qualidade. Outro aspecto foi a semi-estruturação do questionário para a entrevista, que ocorreu por meio de uma sessão de brainstorming com toda a equipe. Foram definidas para o questionário quinze questões-chave, que serviram de referência para a condução da entrevista, com campos relacionados ao estado emocional da pessoa em relação ao desemprego, ao conhecimento sobre o serviço Balcão de Oportunidades Birigui e à experiência de uso. Além disso, definiu-se que apenas um dos pesquisadores iria conduzir a técnica do Think Aloud, evitando qualquer desvio na abordagem. Para melhor realização da técnica, foi realizado um pré-teste, para que se pudesse aferir a dinâmica e o sistema de coleta de informações (MARCONI; LAKATOS, 2010), como a definição das tarefas a serem executadas pelo participante e a captação dos dados: anotações e gravação de áudio.

3. Amostragem: Os participantes atenderam aos requisitos de classificação para o estudo.

4. Think aloud/Observação: O método Think Aloud, traduzido literalmente como pensar em voz alta, consiste na obtenção de dados sobre um processo cognitivo. Através dele, a tarefa pode ser automatizada ou verbalizada por uma pessoa. Trata-se de um protocolo relevante no tocante aos aspectos referentes à resolução de problemas e que são acessíveis para verbalização (SOMEREN; BARNARD; SONDBERG, 1994).

Assim sendo, foi solicitado aos participantes da pesquisa que, ao realizar algumas tarefas no sistema, fizessem comentários sobre suas opiniões acerca das ações realizadas. Dessa forma, pode-se observar as tarefas e relacioná-las aos apontamentos dos participantes. Neste caso, as tarefas definidas foram: $1^{\circ}$ - 
Navegação livre pelo site; $2^{\circ}$ - Busca por uma vaga; $3^{\circ}$ - Candidatura à uma vaga através do Login; $4^{\circ}$ - Alteração de dados cadastrais. As tarefas eram apresentadas e não havia manifestação quanto a plataforma ou dúvidas de usabilidade. Além disso, o participante era constantemente estimulado a relatar verbalmente o que estava pensando e a descrever as ações que estava executando. Fez-se uso da gravação de áudio e das anotações do pesquisador.

5. Entrevistas/Observação: As entrevistas semi-estruturadas ocorreram logo após o Think Aloud, para tornar o processo mais ágil e obter informações mais recentes da memória do participante. A psicóloga conduziu a pesquisa estimulando a contação de histórias acerca das situações solicitadas, deixando a entrevista mais natural e menos inflexível.

6. Interpretação: Após realizadas as duas técnicas com cada participante, os áudios foram compartilhados com os membros da equipe que, individualmente, faziam anotações de suas percepções. Na sequência, foram realizadas reuniões para compartilhamento e discussão, a fim de se estabelecer o consenso acerca das informações-chave coletadas.

Mapa da experiência do usuário: Mapas de experiência concentramse na visualização das experiências de usuário em ordem cronológica durante um processo de utilização de um sistema. Seu principal objetivo é entender o comportamento humano frente a essa vivência (GIBBONS, 2017). A fim de se facilitar a apreciação dos dados, os estágios do mapa foram divididos em itens e subdivididos em touchpoints, de acordo com a tabela 1.

Tabela 1 - Planejamento do mapa de experiência do usuário

\begin{tabular}{|c|c|c|c|c|c|c|c|c|}
\hline Estágio & \multicolumn{2}{|c|}{ Busca por vagas } & \multicolumn{2}{c|}{ Candidatura } & \multicolumn{2}{c|}{ Alteração de dados cadastrais } \\
\hline Touchpoint & $\begin{array}{c}\text { Procura } \\
\text { por } \\
\text { vagas }\end{array}$ & Vagas & Análise & Login & $\begin{array}{c}\text { E-mail de } \\
\text { confirmação }\end{array}$ & $\begin{array}{c}\text { Login/ } \\
\text { Alterar } \\
\text { dados }\end{array}$ & $\begin{array}{c}\text { Campo a } \\
\text { ser } \\
\text { alterado }\end{array}$ & Encerramento \\
& & & & & & & & \\
& & & & & & & \\
\hline
\end{tabular}

Fonte: Elaborado pelos autores. 
Projética, Londrina, v. 12, n. 1, p. 195-219, março 2021

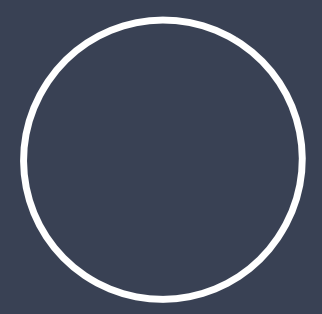

A questão principal é a usabilidade que vai permitir que se coloque os usuários no centro de seu processo de desenvolvimento, eliminará a ambiguidade $e$ chegará ao ponto central de suas necessidades (LOWDERNILK, 2013) 
7. Triangulação: A triangulação é uma importante estratégia de validação para a confirmação de dados coletados utilizando diferentes procedimentos de forma combinada ou mista, cujo propósito é obter estudos e procedimentos revisados e corrigidos pelos próprios participantes. Dessa forma, para garantir a confiabilidade e a confirmabilidade, a descrição detalhada dos resultados pode ser transferível entre os pesquisadores e os indivíduos estudados, da mesma forma que os resultados sejam sujeitos às mudanças e à instabilidade (CRESWELL, 2007).

Para tal, os dados coletados pelos métodos think aloud, entrevistas, observação e mapa de experiência foram depurados e avaliados, de forma a promover maior heterogeneidade de interpretação, análise a fim de evitar o enviesamento. Com isso, foi possível classificar as respostas, para que se identificasse padrões ou similaridade conceitual, de forma a reduzir as variações de dados e melhor organizá-los para a redação do relatório.

8. Relatório: Construção do relatório final da pesquisa.

\subsection{Amostra}

Participaram voluntariamente, após a assinatura do Termo de Consentimento Livre e Esclarecido (TCLE), cinco indivíduos já cadastrados na plataforma do Balcão de Oportunidades Birigui, todos adultos, com idade entre 18 e 40 anos. Todos eram alfabetizados e apresentavam familiaridade com o uso da internet e eram desempregados (Tabela 2).

Tabela 2 - Dados dos participantes da pesquisa $(n=5)$

\begin{tabular}{ccccc} 
Participantes & Gênero & $\begin{array}{c}\text { Idade } \\
\text { (anos) }\end{array}$ & Escolaridade & $\begin{array}{c}\text { Desemprego } \\
\text { (meses) }\end{array}$ \\
\hline P1 & M & 24 & Graduação & 12 \\
\hline P2 & F & 25 & Graduação & 1 \\
\hline P3 & F & 28 & Técnico & 12 \\
\hline P4 & M & 27 & Ensino Médio & 1 \\
\hline P5 & F & 36 & Graduação & 2
\end{tabular}

Fonte: Elaborado pelos autores. 


\section{RESULTADOS}

\subsection{Think Aloud/Observação}

Poucos problemas técnicos foram identificados na plataforma. Os usuários, em sua totalidade, a interface agradável e de fácil navegação. No entanto, ao tentar utilizar os filtros, a maior parte dos participantes demorou para escolher a cidade onde gostaria de ver as vagas, e um deles relatou "Esta parte me deixa confusa". Isso ocorreu, pois a interface apresenta dois campos diferentes de filtro para localidades, como indicado na Figura 1, pelas demarcações A e B. Os usuários não sabiam se era correto digitar o cargo e filtrar o Estado ou, clicar diretamente no filtro $B$, para aqueles que moravam em Birigui.

Figura 1 - Tela de busca de vagas do Balcão de Oportunidades Birigui, com as observações "A" e "B" (em vermelho).

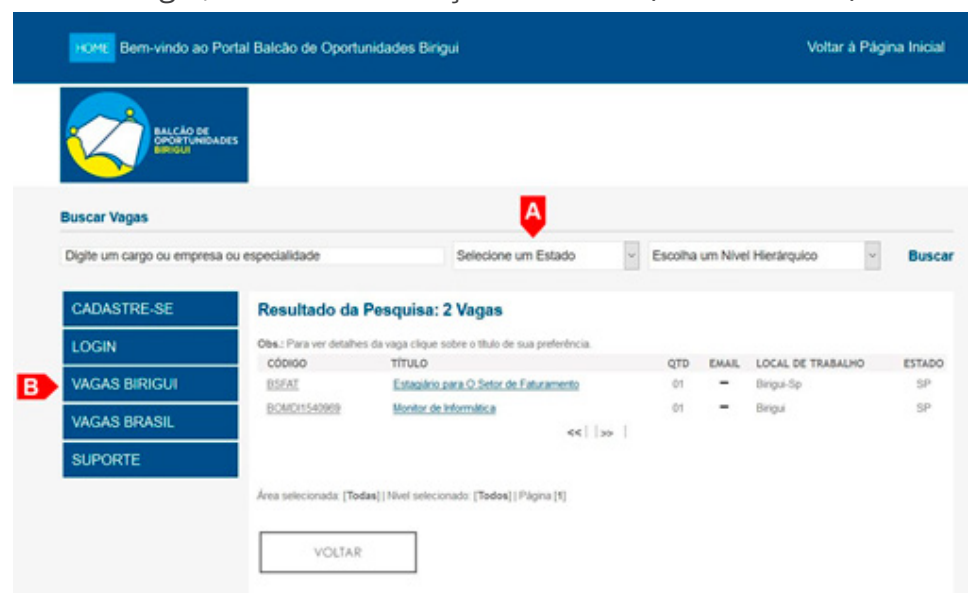

Fonte - Adaptado pelos autores, 2018.

Outro aspecto relatado pela maioria dos participantes foi o fato de haver vagas expiradas no site, em que alguns deles já tinham se candidatado há alguns meses, e não receberam retorno até aquele momento. Houve questionamento acerca do acompanhamento das vagas por todos os participantes, que apontaram a 
falta de transparência e de respeito em não dar um retorno final sobre sua situação no processo seletivo. Alguns relatos foram: "A vaga não expira"; "Como posso saber se a empresa recebeu meu e-mail?"; "Após o login, minhas candidaturas não aparecem no perfil".

A plataforma se mostrou bem conhecida no meio das pessoas que buscam emprego na região, no entanto, para os usuários desempregados, há mais de seis meses, que são usuários recorrentes da plataforma, o serviço deve estar ficando obsoleto, pois as vagas não se renovam e eles acreditam que as empresas não devem estar utilizando o sistema. Essa afirmação surgiu de pelo menos dois entrevistados, que relataram utilizar outro serviço virtual regional e privado de vagas de emprego, a Solutudo ${ }^{3}$. Para os usuários, as vagas da Solutudo, além de serem em número muito maior ${ }^{4}$, são renovadas constantemente e divulgadas nas redes sociais.

Outro aspecto criticado por dois participantes foi o fato de o perfil exigir uma quantidade muito grande de informações pessoais, até mesmo documentação. Um dos entrevistados fez o seguinte relato: "A dúvida que tive era se o site era confiável, porque têm campos que pedem seu nome, RG, CPF [...]". O entendimento dos participantes é o de que a internet é perigosa e estes dados podem deixá-los vulneráveis.

Uma dúvida que os participantes tinham, durante o acesso ao site pelo notebook, foi o fato de não saberem se a plataforma tinha um aplicativo para smartphone. Com exceção de um participante, eles não sabiam se era possível acessar pelo celular, pois realizaram o cadastro e fizeram suas buscas, até o momento, pelo notebook. O participante que tentou acessar pelo celular reportou a seguinte crítica: “[...] no celular, quando eu me candidato, eu tenho dificuldades [...], aí o aviso de se candidatar aparece bem pequeno e eu achei meio ruim [...]".

[3] Acesso à plataforma: www.solutudo.com.br

[4] No dia 12/01/2019, data de finalização deste artigo, foram apontadas 50 vagas de emprego na plataforma Solutudo, enquanto o Balcão de Oportunidades Birigui dispunha de apenas duas. 
Como pontos positivos, os participantes acharam a interface muito clara e simples, pois não apresenta complexidade nas operações. Além disso, quando as candidaturas são realizadas, eles recebem um e-mail de confirmação da empresa que desenvolveu e hospeda a plataforma, a Elancers. Isso, por outro lado, gerou um questionamento na equipe, pois um entrevistado fez questão de falar que o remetente não era o Balcão de Oportunidades Birigui.

Por fim, o levantamento através do Think Aloud trouxe uma série de questionamentos da equipe de pesquisa, mesmo diante da tranquilidade dos usuários durante o teste. Estes apontamentos deixaram claro que a plataforma não contempla todas as necessidades dos usuários.

\subsection{Entrevista/Observação}

Uma das características mais marcantes desta etapa é o fato de que as pessoas relatam mais a experiência total e o impacto dela em suas vidas, dando menor importância a detalhes do uso. Indiretamente, os entrevistados apontaram o quanto seu lado emocional está abalado, em função do desemprego e o quanto há frustrações na busca de empregos através da plataforma Balcão de Oportunidades Birigui.

O grande descontentamento pelos usuários é: “Não sei como acontece o trâmite por trás da plataforma", isto é, o site não dá detalhes do envio e confirmação de recebimento, por parte da empresa. Além disso, não há recursos de acompanhamento do processo seletivo e tampouco amarrações entre a chamada para as entrevistas presenciais e o site. Dois candidatos relataram já terem passado por entrevistas e não saberem se o convite se originou pelo site ou pelo envio de currículos. O envio de currículos foi outra questão levantada na pesquisa, pois dois usuários assumiram enviar o currículo por e-mail, mesmo tendo realizado a submissão pelo site. Isso denota a falta de confiança na plataforma. 
Por não serem chamados ou não terem um retorno da finalização do processo seletivo, os usuários assumiram se sentirem frustrados, pois as expectativas criadas foram grandes. A ausência de feedback e o número reduzido de vagas se sobressaíram nos discursos, durante a entrevista. Os usuários, em sua maioria, sentem que a plataforma é pouco explorada pelas empresas e alguns não sabem quem cuida do sistema.

Relatos positivos também foram muito observados na entrevista, como o fato de os entrevistados acharem a plataforma importante, pois facilita muito a vida de quem procura emprego. Um entrevistado relatou sobre a vantagem de usar o site da seguinte forma: “É uma oportunidade para quem está procurando emprego de não só ficar batendo perna na rua, porque a gente ficar só batendo perna na rua, não sei se surte tanto efeito quanto o site". No entanto, a necessidade apontada por eles é o acesso pelo celular, pois facilitaria a busca em função de estarem o dia todos conectados, diferentemente do notebook, pois o site não é responsivo (ajustável à tela do celular).

De modo geral, os relatos positivos giraram em torno da qualidade visual e da simplicidade da plataforma, da esperança que ela cria ao apresentar oportunidades para aqueles que procuram emprego. Contudo, como relatado anteriormente, há necessidade de uma revisão do fluxo do serviço, tanto nos pontos virtuais quanto presenciais, e principalmente na questão transparência nas informações. A plataforma não deixa claro o processo seletivo e não dá qualquer feedback para o usuário, que possivelmente vai transformar sua esperança em frustração.

\subsection{Troca de Percepções}

Esta reunião ocorreu com a equipe que realizou a pesquisa diretamente com os usuários, e seu objetivo foi gerar discussão sobre os dados coletados, por meio da troca de percepções, visando o consenso no entendimento dos pontos críticos. 
Projética, Londrina, v. 12, n. 1, p. 195-219, março 2021

Ao se analisar a experiência do usuário em um determinado software, deve-se levar em consideração tanto os iniciantes quanto os usuários experientes, e sua interface deve propor diferentes meios para que ambos tenham facilidade de usar suas funções, sem a necessidade de personalizáIas (CYBIS; BETIOL; FAUST, 2015). 
Outro aspecto importante destes encontros é o alinhamento dos pesquisadores em relação à importância das informações geradas e o olhar para as hipóteses iniciais, de forma coletiva.

Como apresentado na figura 2, a sessão foi realizada para o compartilhamento das percepções dos pesquisadores e da psicóloga, acerca da entrevista e do Think Aloud. Foram discutidas todas as informações relevantes, anotadas durante as técnicas e durante a audição das gravações de voz. O objetivo deste encontro foi identificar padrões de respostas entre os usuários.

Figura 2 - Sessão de troca de percepções e análise das informações.

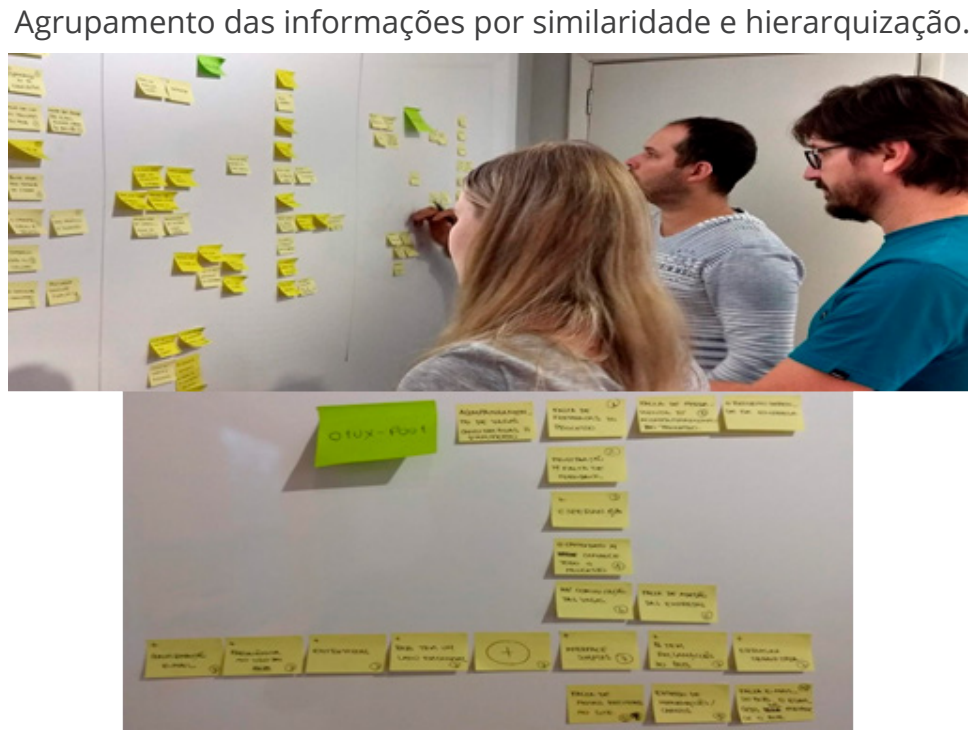

Fonte - os autores, 2018.

Para o desenvolvimento desta sessão, foi determinado que cada pesquisador relatasse uma percepção por vez, que deveria ser conferida pelos outros participantes da sessão, a fim de se obter o consenso do grupo em relação à manutenção, ajuste ou exclusão da informação. Neste sentido, poucas informações foram excluídas, algumas alteradas e a maioria colocada em post-its e fixadas no painel. Após inseridas todas as informações de cada usuário, estabeleceu-se 
a conexão entre algumas informações por meio da similaridade, em que foram formados grupos de post-its. Cada grupo constitui uma característica da experiência de cada usuário, que foram hierarquizados de acordo com grau de importância, dado pelo grupo, em relação à experiência global do usuário.

Os temas identificados em cada usuário foram alinhados aos mesmos dos outros usuários, facilitando a identificação dos padrões e corroborando a percepção dos pesquisadores em relação aos pontos críticos do serviço. Mesmo que com poucos usuários, os temas-chave foram se repetindo em todos os participantes, apontando-se similares nas insatisfações e nos pontos positivos. Por isso, a participação de uma psicóloga foi importante para o processo, pois ajudou os pesquisadores a melhor entender causa e efeito de algumas externalizações verbais dos entrevistados.

\subsection{Mapa da Experiência dos Usuários}

Após realizada a sessão de troca de percepções entre os pesquisadores, foi criado o mapa da experiência dos usuários do Balcão de Oportunidades Birigui, em que foi possível identificar cada momento em que algumas observações, críticas e elogios dos participantes surgiram. Das técnicas utilizadas neste estudo, o mapa se destaca como a forma mais visual e quantitativa empregada, pois parte do preenchimento de campos padrões para todos os dados, dando condição de se identificar as diferenças entre os participantes.

O mapa utilizado neste estudo é composto por cinco campos principais (figura 3), sendo eles os Estágios, que são as tarefas solicitadas aos participantes, os Touchpoints, que são os contatos com os recursos da plataforma, o Touchpoint Info, que se refere ao detalhamento do Touchpoint, as Ações, que são as atividades executadas pelos usuários e o campo Experiência Emocional, que é onde cada um 
teve medido o seu nível de satisfação ao passar por diversas etapas das tarefas. Os quatro campos superiores foram organizados com base na experiência dos pesquisadores com a plataforma, juntamente com o sequenciamento das ações dos usuários, durante a pesquisa.

Figura 3 - Mapa da experiência dos usuários

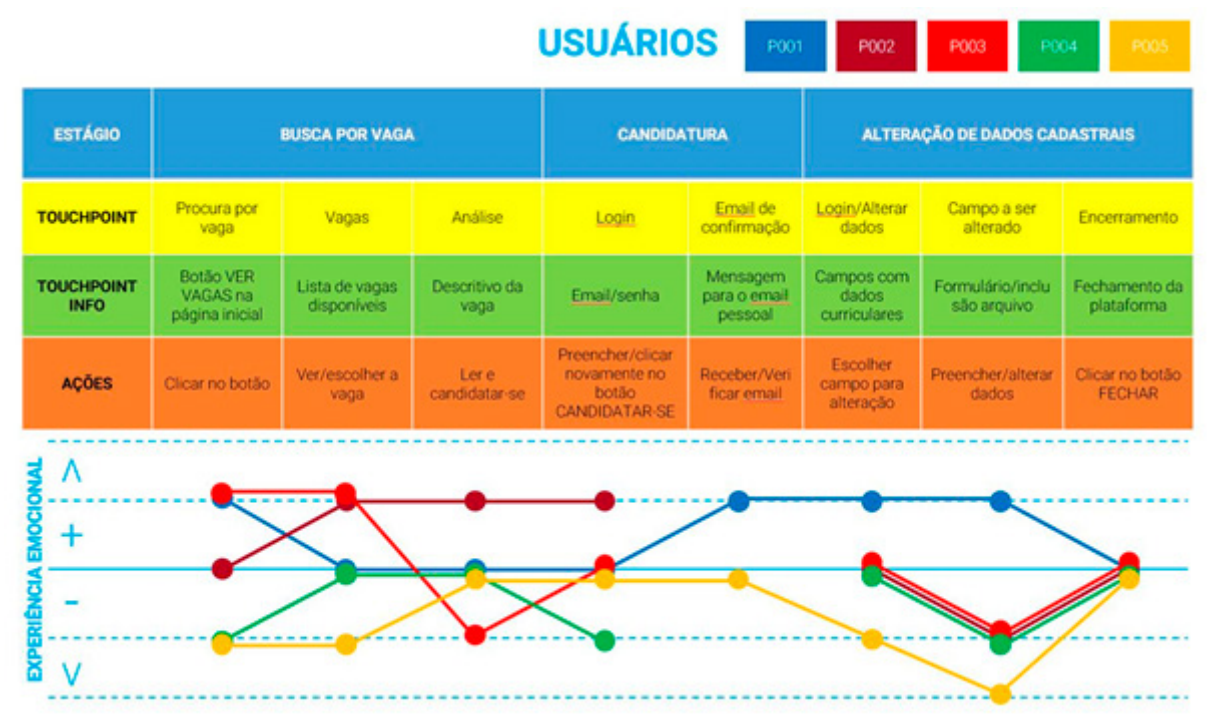

Fonte - os autores, 2018.

Os níveis de experiência de cada etapa, identificados por cores diferentes para cada usuário, foram determinados após análise dos áudios dos Think Alouds por todos os pesquisadores e, durante a sessão de troca de percepções, cada Touchpoint foi discutido separadamente e sua respectiva pontuação foi discutida até que se chegasse ao consenso. Cada usuário ganhou sua curva de experiência a partir do cruzamento das informações das duas técnicas, pois a entrevista semiestrutura reforçou uma série de apontamentos do Think Aloud.

Observando-se o campo Experiência Emocional, mesmo sendo uma análise, de certa forma, subjetiva, nota-se que poucos momentos apresentaram experiências muito positivas para os usuários. Na verdade, há uma concentração maior de 
classificações neutras (linha mediana) e negativas, principalmente no último estágio "Alteração dos dados cadastrais". Para alguns usuários, não foi possível inserir foto pessoal, pois o sistema apresentava erro, havendo críticas nesta funcionalidade e outro relatou não conseguir ver todo o currículo. Nesta etapa, foram apontadas, ainda, as questões dos dados pessoais, pois são solicitadas muitas informações. O contraponto para que o mapa tivesse uma classificação mediana-negativa foi a avaliação do usuário de cor azul (P001), que, neste caso, é um jovem formado em Análise e Desenvolvimento de Sistemas, e tem alto conhecimento em informática. Isso pode ser um fator influenciador na avaliação, pois alguns problemas técnicos foram facilmente superados.

O que se nota, de modo geral, é que a experiência não é totalmente negativa para os usuários. Isso corrobora as afirmações dadas pelos participantes, de que o site é simples e de fácil uso. A interface, mesmo apresentando algumas incoerências, tem bom desempenho perante aqueles que a utilizam. Entretanto, há uma série de oportunidades, de fácil implementação, que poderiam aumentar o grau de satisfação e confiabilidade dos usuários, especificamente durante a jornada na plataforma virtual.

\subsection{Triangulação}

O compartilhamento dos dados foi realizado com todos os integrantes do grupo de pesquisa e as informações provindas de cada técnica foram confrontadas. De modo geral, os pesquisadores concordaram com as conclusões da sessão de troca de percepções e com a construção do mapa da experiência do usuário. Entretanto, foi sugerido que alguns campos fossem adicionados ao mapa, mais especificamente campos de indicação de oportunidades. Neste caso, foi adicionada uma seção com campos para que se acrescentassem ideias de melhoria na plataforma, que foram definidas consensualmente entre os pesquisadores (figura 4). 
Figura 4 - Identificação das oportunidades de melhoria na experiência do usuário.

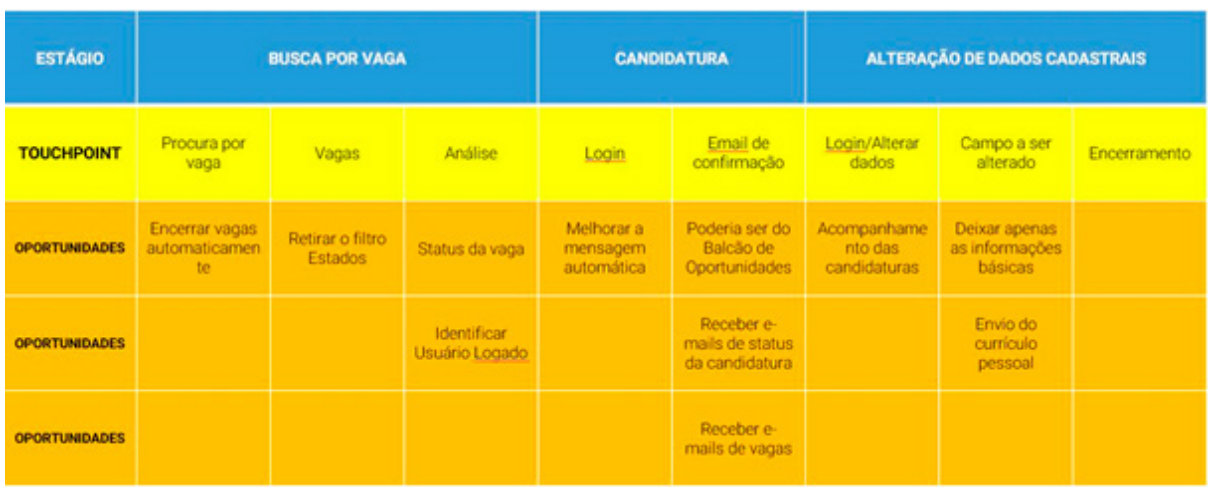

Fonte - Elaborado pelos autores, 2018.

As sugestões apresentadas na figura 5 são apenas acerca da plataforma, contudo, há uma enormidade de melhorias e oportunidades de inovação identificadas pelos pesquisadores em relação a todo o serviço prestado pelo Balcão de Oportunidades Birigui. Pontos como feedback periódico do processo seletivo, e-mails com oportunidades de emprego, geração de conteúdo e/ou blog com dicas de desenvolvimento profissional, parceria com instituições de ensino etc. Especificamente sobre a interface, os pontos indicados na tabela visam minimizar as insatisfações mais latentes dos usuários, como a possibilidade de acompanhar visualmente seu processo de candidatura, reduzir o número de informações pessoais solicitadas, pois isso não é relevante durante o processo, mas sim, apenas depois da contratação, e outras sugestões mais, de fácil implementação.

\section{CONSIDERAÇÕES FINAIS}

A busca por empregos pela internet é uma atividade muito comum na atualidade e tem substituído substancialmente a interação entre trabalhadores desempregados e setores de Recursos Humanos. A tecnologia tem se mostrado 
uma importante ferramenta para aqueles que buscam recolocação no mercado, devido à possibilidade de filtragem e agilidade no processo. Este estudo, de caráter qualitativo, avaliou a experiência de usuários de uma plataforma virtual de busca de empregos, chamada Balcão de Oportunidades Birigui. Para o desenvolvimento do estudo, foram utilizadas técnicas da área de UX e design centrado no usuário.

Os resultados apresentam uma série de insatisfações dos usuários em relação tanto à plataforma quanto ao serviço, que se estende presencialmente. Especificamente a plataforma, são identificados problemas de usabilidade e funcionalidade, como a inadequação ao uso pelo celular, problemas no cadastro de informações pessoais e outros. Contudo, os principais problemas apresentados são de ordem psicológica e emocional, impactados pela falta do uso de princípios básicos de UX no design da interface, como por exemplo, a possibilidade de o usuário acompanhar o processo seletivo ao qual se candidatou.

Os princípios de UX indicam que, primordialmente, os usuários devem se sentir satisfeitos ao utilizar um sistema, funcional e emocionalmente. Isso não ocorre com o Balcão de Oportunidades Birigui, pois deveria gerar esperança nas pessoas desempregadas, mas que, por falta de feedback, transparência e consistência na prestação do serviço, causa frustração para aqueles que não obtêm resposta (tanto positiva quanto negativa). Por fim, é importante frisar, que o serviço tem um alto potencial de adesão da população, pois tem um papel muito importante econômica e socialmente. No entanto, são necessárias adequações no design da interface da plataforma, considerando a aplicação dos princípios de UX.

\section{Agradecimentos}

À psicóloga Débora Bertão da Silva, pelo auxílio na condução das entrevistas com os participantes do estudo. 


\section{REFERÊNCIAS}

1. BONI, Valdete; QUARESMA, Sílvia Jurema. Aprendendo a entrevistar: como fazer entrevistas em Ciências Sociais. Revista Eletrônica dos Pós-Graduandos em Sociologia Política da UFSC, Florianópolis, v. 2, n. 1, p. 68-80, 2005.

2. CRESWELL, John W. Qualitative inquiry \& research design: choosing among five approches. 2. ed. London: Sage Publications, 2007.

3. CYBIS, Walter de Abreu; BETIOL, Adriana Holtz; FAUST, Richard. Ergonomia e usabilidade: conhecimentos, métodos e aplicações. 3. ed. São Paulo: Novatec, 2015.

4. FARINA, Anete Souza; NEVES, Tatiana Freitas S. das. Formas de lidar com o desemprego: possibilidades e limites de um projeto de atuação em psicologia social do trabalho. Cadernos de Psicologia Social do Trabalho, São Paulo, SP, v. 10, n. 1, p. 21-36, 2007.

5. GIBBONS, Sarah. UX mapping methods compared: a cheat sheet. Fremont, CA: Nielsen Norman Group, 2017. Disponível em: https://www.nngroup.com/ articles/ux-mapping-cheat-sheet/. Acesso em: 4 jan. 2019.

6. HESS, Whitney. STARTUXS. 52 Weeks of UX. Week 29. 2010. Disponível em: https://52weeksofux.com/post/890289075/startuxs. Acesso em 5 nov. 2019.

7. IBGE. Pesquisa nacional por amostras de domicílio contínua: terceiro trimestre 2018. Rio de Janeiro: IBGE, 2018. Disponível em: https://biblioteca. ibge.gov.br/visualizacao/periodicos/2421/pnact_2018_3tri.pdf. Acesso em 3 jan. 2019. 
Projética, Londrina, v. 12, n. 1, p. 195-219, março 2021

8. JEN, Benjamim; KAUR, Jashanjit; DE HEUS, Jonathan; DILLAHUNT, Tawanna R. Analyzing Employment Technologies for Economically Distressed Individuals. In: CHI: Conference on Human Factors in Computing Systems, 2014, Toronto, Ontario, Canada. Proceedings [...]. New York: Association for Computing Machinery, 2014. p. 1945-1950.

9. LOWDERNILK, Travis. Design centrado no usuário: um guia para o desenvolvimento de aplicativos amigáveis. São Paulo: Novatec Editora, 2013.

10. MANYIKA, James. Technology, jobs, and the future of work: briefing note. New York, NY: Mckinsey Global Institute, 2017. Disponível em: https://www. mckinsey.com/featured-insights/employment-and-growth/technology-jobsand-the-future-of-work. Acesso em 3 jan. 2019.

11. MARCONI, Marina de Andrade; LAKATOS, Eva Maria. Fundamentos de metodologia científica. 7. ed. São Paulo: Atlas, 2010.

12. MENEZES JUNIOR, A.; RAMOS, C. H. G.; FERNANDES, D. L.; RUZZANTE, G.; KOGA, R.; OLIVEIRA NETO, S.; OLIVEIRA, T. A. O problema do desemprego: como ele é trazido até o serviço de aconselhamento psicológico do Instituto de Psicologia da USP. São Paulo: Instituto de Psicologia, Universidade de São Paulo, 1999. Relatório de estágio. Não publicado.

13. NIELSEN, Jakob; LANDAUER, Thomas K. A mathematical model of the finding of usability problems. In: INTERACT'93; CHI: CONFERENCE ON HUMAN FACTORS IN COMPUTING SYSTEMS, 1993, Amsterdam. Proceedings [...]. New York, NY: Association for Computing Machinery, 1993. p. 206-213. 
14. NOJıMOTO, Cynthia. Design para experiência: processos e sistemas digitais. 2009. 212 f. Dissertação (Mestrado em Arquitetura e Urbanismo) - Escola de Engenharia, Universidade de São Paulo, São Carlos, SP, 2009.

15. POCHMANN, Márcio. O trabalho na crise econômica no Brasil: primeiros sinais. Estudos Avançados, São Paulo, v. 23, n. 66, p. 41- 52, 2009.

16. RIBEIRO, Hugo. Usabilidade acessível: metodologia para avaliação qualitativa da usabilidade no Design para web. 2012. Dissertação (Mestrado em Design da Imagem) - Faculdade de Belas Artes, Universidade do Porto, Porto, Portugal, 2012.

17. SATO, Leny; SCHMIDT, Maria Luísa Sandoval. Psicologia do trabalho e psicologia clínica: um ensaio de articulação focalizando o desemprego. Estudos de Psicologia, Campinas, SP, v. 9, n. 2, p. 365-371, 2004.

18. SOMEREN, Maarten W. van; BARNARD, Yvonne F.; SANDBERG, Jacobijn A. C. The think aloud method: a practical guide to modelling cognitive processes. London: Academic Press, 1994.

19. TEIXEIRA, Fabricio. Introdução e boas práticas em UX Design. São Paulo: Casa do Código, 2013.

20. TERRA, Carolina Passos; CARVALHO, Joari Aparecido Soares de; AZEVEDO, José Eduardo Assunção; VENEZIAN, Luciana de Albuquerque; MACHADO, Sérgio Bacchi. Desemprego: discurso e silenciamento: um estudo com clientes de um serviço de aconselhamento psicológico. Cadernos de Psicologia Social do Trabalho, São Paulo, SP, v. 9, n. 1, p. 33-51, 2006. 